\title{
INCIDENCE OF ACUTE CORONARY SYNDROME AFTER TRAUMATIC BRAIN INJURY IN INTENSIVE CARE UNIT (ASSOCIATED FACTORS AND MORTALITY): A RETROSPECTIVE STUDY
}

\author{
Adel. E. Diab ${ }^{1}$, Mahmoud. H. Hussein ${ }^{2}$, Amal. A. Ahmed ${ }^{3}$ \\ ${ }^{1}$ Assistant Professor of anesthesia and Intensive care Department \\ ${ }^{2}$ Assistant Professor of Forensic Medicine and Clinical Toxicology \\ ${ }^{1,2}$ Faculty of Medicine (Al-Azar University, Damietta) \\ ${ }^{3}$ Assistant Professor of Forensic Medicine and Clinical Toxicology, \\ Faculty of Medicine for Girls (Al-Azar University, Cairo).
}

Corresponding author: Amal Abdel Megeed Ahmed, Forensic Medicine and Clinical Toxicology Department, Faculty of Medicine for Girls. (Al-Azhar University, Cairo). 01284567948; amal.mohamed53@yahoo.com

\begin{abstract}
Background: Although the association between traumatic brain injury (TBI) and cardiac diseases were reported previously, the incidence of acute coronary syndrome (ACS) (per se) was not fully elucidated. The aim of this work was to estimate the incidence of ACS, associated factors and mortality during the first week of admission in patients with TBI admitted to intensive care unit (ICU). Patients and Methods: This retrospective study included all adult patients with TBI admitted to ICU (Al-Azhar University Hospital, Damietta), during (2016-2018). Patients with a history of cardiac comorbidity, those who had associated chest, abdominal trauma, or bone fractures, were excluded. The collected data included: patient demographics, ICU clinical and laboratory data and history of chronic diseases. In additions, serum Troponin I, Glasco coma scale (GCS), electrocardiogram (ECG), echocardiographic examination, and patients' outcome were recorded. patients were divided into two groups according to the development of ACS the first included those who developed ACS and the second included those who did not develop ACS. Results: Of the 90 patients with TBI admitted to ICU, ACS was developed in (30.0\%), age was $(68.7 \pm 6.4)$, chronic diseases $(40.7 \%)$. GCS was significantly lower in ACS group. Tachycardia, hypertension and hypernatremia was documented at admission. RBCs, hemoglobin and platelet count were significantly decreased while INR and PTT were elevated in ACS at admission and at $7^{\text {th }}$ day. ECG changes in ACS group were in the form of ST elevation, ST depression and hyperacute T wave. Significant elevated troponin and abnormal echocardiographic findings were found in ACS group. Finally, significant increased mortality during the first week of admission in ACS compared to negative group (29.6\% vs 3.2\% respectively). Conclusions: These results documented the development of ACS after TBI and associated with older age, increased chronic disease, severity of trauma, hemodynamic instability, coagulopathy and increased ICU mortality. Search for ACS and identification of high-risk patients after
\end{abstract}


TBI are crucial to prevent cardiac morbidity and mortality. Otherwise, physicians could be exposed to medical negligence claims.

Keywords: Traumatic brain injury, ECG changes, Acute Coronary Syndrome, Cardiac Troponin I, Echocardiography.

\section{INTRODUCTION}

Traumatic brain injury (TBI) represent a significant etiology of death disability. About 13 million people live with disabilities due to TBI in Europe and United States of America. Severe TBI was confined to $10-15 \%$ of patients who need special care, and usually managed in the intensive care unit (ICU) with a combination of medical and surgical approaches (Stocchetti et al., 2017).

In TBI, the heart could be affected directly as a part of polytrauma, or indirectly by trauma-induced hypotension with coronary hypoperfusion. In addition, the stress of trauma induces catecholamine surge and release of inflammatory mediators that could harm cardiac myocytes (Salim et al., 2008).

In addition, TBI can disturb the autonomic nervous system, with subsequent cardiac dysfunction (Leitman, 2012).

The brain heart link could be explained by neurocardiac axis theory and neurogenic stunned myocardium phenomenon, with better understand and management of TBI (Cai et al., 2016).

The decreased blood to the coronaries with catecholamine surge may lead to acute coronary syndrome (ACS), which is a set of signs and symptoms due to harmful effect on cardiac muscle leading to its malfunction or even death (Amsterdam et al., 2014).

ACS usually presents by chest pain, radiating to the left shoulder, sense of tightness, with nausea and sweating.
Atypical presentation was reported especially in women old people, and patients with diabetes mellitus. The diagnosis depends on clinical presentation, changes in ECG, increased troponins and detection of wall abnormalities by echocardiography (Thygesen et al., 2012).

Although the association between TBI and cardiac diseases were reported previously, the incidence of ACS (per se) was not fully elucidated. The aim of the work to estimate the incidence of acute coronary syndrome, associated factors and mortality during the first week of admission in patients with traumatic brain injury admitted to intensive care unit.

\section{PATIENTS AND METHODS}

We retrospectively analyzed files of all adult patients ( $\geq 18$ years) admitted to intensive care unit (Al-Azhar University Hospital, Damietta), during the last 3 years (2016-2018). Inclusion criteria specified adult patients of $\geq 18$ years of age that have received a diagnosis of TBI verified by magnetic resonance imaging (MRI). Exclusion criteria included; Patients aged below 18 years, Patients with a history of cardiac co-morbidity (defined as documented preadmission coronary artery disease, myocardial ischemia/ infarction, arrhythmia, heart failure, untreated hypertension and cardiac pacemaker), a past medical history of cardio-thoracic surgery or significant cardiovascular stroke. Also, patients with extracranial injuries such as (those who 
had associated chest, abdominal trauma, bone fractures) or an expected brain death were excluded from the study (Cuisinier et al., 2016). The study protocol was approved by the Local Research and Ethics Committee of Al-Azhar University (number: ADFM-IRB05082018). The collected data included the following: patient demographics (age and gender), history of chronic medical diseases (cancer, diabetes, hepatitis, and chronic kidney disease) and previous surgery. The severity of brain injuries assessed by Glasgow coma scale (GCS) at admission (Esterov and Greenwald, 2017).

In additions, results of clinical examination and ICU monitoring of heart rate, mean arterial blood pressure, and oxygen saturation during the first week of admission (at admission and at $7^{\text {th }}$ day). Also, results of laboratory investigations such as complete blood count, liver function tests, kidney function tests and coagulation profile were searched for and documented. Finally, results of 12-lead ECG, serum troponin (at 24 hours and 72 hours) and trans-thoracic echocardiography were included in the assessment (Hasanin et al., 2016).

After collection and organization of data, patients were divided into two groups according to the development of acute coronary syndrome during ICU admission; the first included those who developed ACS and the second included those who did not develop ACS. Mortality during the first week were documented and included in the analysis.

Statistical analysis of data: the collected data were prepared and entered in an excel sheet; then coded and transferred to statistical package for social science (SPSS) program, version 18
(IBM $^{\circledR}$ SPSS $^{\circledR}$ Inc., USA). Quantitative data were expressed as mean \pm SD (Standard deviation), while qualitative data were presented as frequency (number) and percent distribution. For purpose of comparison between groups, independent samples student (t) test, and Chi square test were used for quantitative and qualitative data respectively. $\mathrm{P}$ value $<0.05$ was considered significant. In the present work, the receiver operating characteristic (ROC) methodology was employed and the area under the ROC curve (AUC) was calculated to evaluate the predictive accuracy of ACS development and mortality in patients with (TBI). The higher AUC values can be interpreted as having a higher predictive accuracy. Additionally, sensitivity and specificity were measured (Linden, 2006). For evaluation of risk factors of ACS in TBI patients, a regression analysis was performed.

\section{RESULTS}

Acute coronary syndrome was developed in 27 patients $(30.0 \%)$. Patients who developed ACS were significantly older in age when compared to negative group $(68.7 \pm 6.4$ vs $61.3 \pm 4.4$ years respectively). Additionally, AUC of 0.85 for Age indicated a good predictors of ACS development in patients with (TBI) Table (1, 4). ACS was also associated with significant increased history of chronic disease $(40.7 \%$ vs $20.6 \%)$ and GCS was significantly lower in ACS group (6.4 \pm 1.2 vs $7.2 \pm 0.9)$. However, TBI was associated with male gender where males represented $63 \%$ and $81 \%$ of ACS and negative groups respectively, with no significant difference between groups. In addition, there was no significant 
difference between both groups regarding history of previous surgery (Table1).

Table (2) presented hemodynamic and laboratory data among studied populations and revealed that, ACS group had significantly faster heart rate and higher mean arterial pressure at admission, but at the $7^{\text {th }}$ day both groups were comparable. In addition, there was statistically significant decrease of RBCs, hemoglobin, platelet count, at admission and at the $7^{\text {th }}$ day in ACS group when compared to negative group. However, serum sodium was significantly increased in ACS group at admission, but not at $7^{\text {th }}$ day. Furthermore, both INR and PTT were significantly increased in ACS at admission and at $7^{\text {th }}$ day. AUC values for $\mathrm{HR}, \mathrm{HB}$ and INR at admission were $0.892,0.896$ and 0.848 respectively which reflects a good predictive accuracy and the stronger the positive association between HR, HB, INR and ACS (Table 4).

The $p$-values for the coefficients confirmed these results and revealed a statistically significant association between several variables and ACS in patients with TBI, including age, low GCS, low HB, higher mean arterial pressure, higher INR, higher sodium and long PTT at admission suggesting the influence of those factors on the development of ACS in patients with TBI (P < 0.05) Table (6).

At admission, ECG changes in ACS group were in the form of ST elevation in $(33.3 \%)$, ST depression in $(55.6 \%)$ and hyperacute $\mathrm{T}$ wave in $(11.1 \%)$. Elevated troponin was significantly increased at 24 and 72 hours in ACS group when compared to negative group $(74.1 \%$ vs $30.2 \%)(81.5 \%$ vs $31.7 \%)$ respectively. In addition, abnormal Echocardiographic findings were significantly increased in ACS when compared to negative group (33.3\% vs $6.3 \%$ respectively). Finally, mortality was reported in 10 patients (11.1\%); eight of them were in ACS group and 2 in negative group with significant increase of mortality in ACS when compared to negative group $(29.6 \%$ vs $3.2 \%$ respectively) (Table 3 ). The good predictors for mortality in ACS patients were age, HR, platelets and INR. The average values of AUC for the age, $\mathrm{HR}$ at admission, platelets at admission and INR were 0.868, 0.892, 0.892 and 0.901 respectively (Table 5).

Table (1): Demographic data, history of chronic disease, previous surgery and GCS of the studied patients with TBI and its Statistical significance tests (student t test and Chi square test).

\begin{tabular}{|c|c|c|c|c|c|}
\hline \multicolumn{2}{|l|}{ Variable } & $\begin{array}{c}\text { ACS group } \\
(n=27)\end{array}$ & $\begin{array}{c}\text { Negative group } \\
(\mathrm{n}=63)\end{array}$ & Test & $\mathrm{P}$ value \\
\hline \multicolumn{2}{|c|}{ Age (years) } & $68.7 \pm 6.4 ; 51-78$ & $61.3 \pm 4.4 ; 53-76$ & 6.36 & $<0.001 *$ \\
\hline \multirow[t]{2}{*}{ Gender } & Male & $17(63.0 \%)$ & $51(81.0 \%)$ & \multirow[t]{2}{*}{3.13} & \multirow[t]{2}{*}{0.07} \\
\hline & Female & $10(37.0 \%)$ & $12(19.0 \%)$ & & \\
\hline \multicolumn{2}{|c|}{ History of chronic disease } & $11(40.7 \%)$ & $13(20.6 \%)$ & 3.90 & $0.048^{*}$ \\
\hline \multicolumn{2}{|c|}{ History of previous surgery } & $3(11.1 \%)$ & $9(14.3 \%)$ & 0.16 & 0.68 \\
\hline \multicolumn{2}{|l|}{ GCS } & $6.4 \pm 1.2 ; 4-8$ & $7.2 \pm 0.9 ; 4-8$ & 3.17 & $0.002 *$ \\
\hline
\end{tabular}


Table (2): Hemodynamic parameters and laboratory investigations during the first week of admission in ICU of patients with TBI and their Statistical significance test (student $t$ test).

\begin{tabular}{|c|c|c|c|c|c|c|c|}
\hline & \multicolumn{2}{|c|}{$\begin{array}{c}\text { ACS group } \\
(n=27)\end{array}$} & \multicolumn{2}{|c|}{$\begin{array}{l}\text { Negative group } \\
(n=63)\end{array}$} & \multirow[t]{2}{*}{$\mathbf{t}$} & \multirow[t]{2}{*}{$\mathbf{p}$} \\
\hline & & Mean & S. D & Mean & SD & & \\
\hline \multirow{2}{*}{$\begin{array}{l}\text { *Heart rate }(\mathrm{HR}) \\
\text { beats } / \mathrm{min}\end{array}$} & At admission & 105.0 & 12.2 & 94.1 & 11.0 & 4.18 & $<0.001 *$ \\
\hline & At 7 days & 90.4 & 8.2 & 86.9 & 4.7 & 1.14 & 0.25 \\
\hline \multirow{2}{*}{$\begin{array}{l}\text { *Mean arterial } \\
\text { pressure }(\mathrm{mmHg})\end{array}$} & At admission & 91.9 & 4.2 & 87.5 & 5.6 & 3.68 & $<0.001 *$ \\
\hline & At 7 days & 83.2 & 3.2 & 85.5 & 4.8 & 1.105 & 0.27 \\
\hline \multirow[t]{2}{*}{${ }^{*} \mathrm{O} 2$ saturation } & At admission & 96.7 & 0.9 & 96.8 & 0.8 & 0.56 & 0.57 \\
\hline & At 7 days & 98.6 & 0.5 & 98.3 & 0.8 & 1.57 & 0.12 \\
\hline \multirow{2}{*}{$\begin{array}{l}* \mathrm{RBCs}\left(10^{6} / \mathrm{cu}\right. \\
\mathrm{mm})\end{array}$} & At admission & 3.3 & 0.2 & 3.4 & 0.2 & 3.97 & $<0.001 *$ \\
\hline & At $7^{\text {th }}$ day & 3.2 & 0.2 & 3.3 & 0.2 & 2.39 & $0.019 *$ \\
\hline \multirow{2}{*}{$\begin{array}{l}\text { *Hemoglobin (HB) } \\
\text { g/dL }\end{array}$} & At admission & 11.9 & 0.4 & 12.4 & 0.2 & 6.91 & $<0.001 *$ \\
\hline & At $7^{\text {th }}$ day & 11.7 & 0.4 & 12.1 & 0.2 & 5.23 & $<0.001 *$ \\
\hline \multirow{2}{*}{$\begin{array}{l}* \mathrm{WBCs}\left(10^{3} / \mathrm{cu}\right. \\
\mathrm{mm})\end{array}$} & At admission & 11.58 & 1.60 & 11.4 & 1.5 & 0.60 & 0.55 \\
\hline & At $7^{\text {th }}$ day & 11.4 & 1.9 & 11.5 & 1.5 & 0.11 & 0.91 \\
\hline \multirow{2}{*}{$\begin{array}{l}\text { *Platelets }\left(10^{3} / \mathrm{cu}\right. \\
\mathrm{mm})\end{array}$} & At admission & 182.5 & 46.0 & 223.6 & 15.7 & 6.30 & $<0.001 *$ \\
\hline & At $7^{\text {th }}$ day & 205.1 & 36.3 & 226.4 & 8.2 & 4.33 & $<0.001 *$ \\
\hline \multirow[t]{2}{*}{ *ALT (U/L) } & At admission & 13.6 & 2.7 & 13.2 & 2.3 & 0.72 & 0.47 \\
\hline & At $7^{\text {th }}$ day & 15.6 & 1.9 & 15.0 & 1.2 & 1.71 & 0.09 \\
\hline \multirow{2}{*}{ *AST (U/L) } & At admission & 19.4 & 4.6 & 18.1 & 2.5 & 1.73 & 0.09 \\
\hline & At $7^{\text {th }}$ day & 17.1 & 1.8 & 17.4 & 1.9 & 0.66 & 0.50 \\
\hline \multirow{2}{*}{$\begin{array}{l}\text { *Total bilirubin } \\
(\mu \mathrm{mol} / \mathrm{L})\end{array}$} & At admission & 1.2 & 0.4 & 1.1 & 0.2 & 1.36 & 0.17 \\
\hline & At $7^{\text {th }}$ day & 0.9 & 0.2 & 0.9 & 0.1 & 0.36 & 0.71 \\
\hline \multirow{2}{*}{$\begin{array}{l}\text { *Direct bilirubin } \\
(\mu \mathrm{mol} / \mathrm{L})\end{array}$} & At admission & 0.4 & 0.1 & 0.4 & 0.1 & 1.72 & 0.09 \\
\hline & At $7^{\text {th }}$ day & 0.4 & 0.1 & 0.4 & 0.1 & 0.52 & 0.60 \\
\hline \multirow[t]{2}{*}{ *Urea $(\mathrm{mg} / \mathrm{dl})$} & At admission & 26.5 & 11.6 & 23.5 & 5.3 & 1.66 & 0.10 \\
\hline & At $7^{\text {th }}$ day & 24.3 & 7.7 & 22.8 & 4.8 & 1.03 & 0.30 \\
\hline \multirow[t]{2}{*}{$*$ Creatinine $(\mathrm{mg} / \mathrm{dl})$} & At admission & 1.1 & 0.2 & 1.1 & 0.3 & 0.87 & 0.38 \\
\hline & At $7^{\text {th }}$ day & 1.1 & 0.3 & 1.0 & 0.2 & 1.67 & 0.09 \\
\hline \multirow[t]{2}{*}{ *Sodium $(\mathrm{mEq} / \mathrm{L})$} & At admission & 148.4 & 4.4 & 145.7 & 4.0 & 2.94 & $0.004 *$ \\
\hline & At $7^{\text {th }}$ day & 141.8 & 2.3 & 141.0 & 2.5 & 1.39 & 0.16 \\
\hline \multirow{2}{*}{$\begin{array}{l}\text { *Potassium } \\
(\mathrm{mEq} / \mathrm{L})\end{array}$} & At admission & 4.0 & 0.3 & 4.0 & 0.3 & 0.28 & 0.77 \\
\hline & At $7^{\text {th }}$ day & 4.1 & 0.3 & 4.0 & 0.3 & 0.66 & 0.51 \\
\hline \multirow[t]{2}{*}{ *INR } & At admission & 1.3 & 0.0 & 1.2 & 0.0 & 5.70 & $<0.001 *$ \\
\hline & At $7^{\text {th }}$ day & 1.2 & 0.0 & 1.2 & 0.0 & 4.11 & $<0.001 *$ \\
\hline \multirow[t]{2}{*}{ *PTT/ seconds } & At admission & 26.0 & 3.4 & 24.4 & 1.8 & 2.83 & $0.006 *$ \\
\hline & At $7^{\text {th }}$ day & 25.7 & 2.2 & 24.1 & 1.2 & 4.04 & $<0.001 *$ \\
\hline
\end{tabular}

Quantitative data were expressed as mean \pm SD (Standard deviation)

* significant difference $(\mathrm{P}$ value $<0.05) \quad$ *ICU: intensive care unit

*Normal value for; HR (60-100 beats/min), arterial pressure (90-140 mmHg), HB (12 -16 g/dL), RBCs $\left(4.5-5.9 \times 10^{6} / \mathrm{cu} \mathrm{mm}\right)$, WBC (4.0-10.0 x 10 $/ \mathrm{cu} \mathrm{mm})$, Platelets $\left(150-450 \times 10^{3} / \mathrm{cu} \mathrm{mm}\right)$, AST (0 to 35U/L), ALT (7-56 U/ L), ALP (41 to $\left.133 \mathrm{U} / \mathrm{L}\right)$, total bilirubin (2 to $21 \mu \mathrm{mol} / \mathrm{L}$ ), direct bilirubin (less than $8 \mu \mathrm{mol} / \mathrm{L}$ ), Urea (5 to $20 \mathrm{mg} / \mathrm{dl}$ ), Creatinine (0.6 to $1.2 \mathrm{mg} / \mathrm{dl})$, Na (135 to 145 $\mathrm{mEq} / \mathrm{L}$ ), Potassium (3.5-5.0 mEq/L), international normalized ratio (INR) 1 to 2, Partial Thromboplastin Time (PTT 25-35 seconds). 
Table (3): Cardiac troponin, ECG, Echo changes and mortality during the first week of admission in ICU of patients with TBI with their Statistical significance test (Chi square test).

\begin{tabular}{|c|c|c|c|c|c|c|c|c|c|}
\hline & \multicolumn{2}{|c|}{$\begin{array}{c}\text { Positive } \\
(n=27)\end{array}$} & \multicolumn{2}{|c|}{$\begin{array}{c}\text { Negative } \\
(n=63)\end{array}$} & \multicolumn{2}{|c|}{$\begin{array}{c}\text { Total } \\
(\mathbf{n}=90)\end{array}$} & \multirow[t]{2}{*}{ test } & \multirow[t]{2}{*}{$\mathbf{p}$} \\
\hline & & 0 & $\%$ & 0 & $\%$ & 0 & $\%$ & & \\
\hline \multirow[t]{4}{*}{ ECG } & None & 0 & $0.0 \%$ & 63 & $100.0 \%$ & 63 & $70.0 \%$ & \multirow[t]{4}{*}{90} & \multirow[t]{4}{*}{$<0.001 *$} \\
\hline & ST elevation & 9 & $33.3 \%$ & 0 & $0.0 \%$ & 9 & $10.0 \%$ & & \\
\hline & ST depression & 15 & $55.6 \%$ & 0 & $0.0 \%$ & 15 & $16.7 \%$ & & \\
\hline & Hyperacute T & 3 & $11.1 \%$ & 0 & $0.0 \%$ & 3 & $3.3 \%$ & & \\
\hline \multirow{2}{*}{$\begin{array}{l}\text { Elevated } \\
\text { Troponin(ng/mL) }\end{array}$} & At 24 hours & 20 & $74.1 \%$ & 19 & $30.2 \%$ & 39 & $43.3 \%$ & 14.84 & $<0.001 *$ \\
\hline & At 72 hours & 22 & $81.5 \%$ & 20 & $31.7 \%$ & 42 & $46.7 \%$ & 18.78 & $<0.001 *$ \\
\hline \multicolumn{2}{|c|}{ Abnormal echo findings } & 9 & $33.3 \%$ & 4 & $6.3 \%$ & 13 & $14.4 \%$ & 11.13 & $0.002 *$ \\
\hline \multicolumn{2}{|l|}{ *ICU mortality } & 8 & $29.6 \%$ & 2 & $3.2 \%$ & 10 & $11.1 \%$ & 13.39 & $<0.001 *$ \\
\hline
\end{tabular}

* significant difference $(\mathrm{P}$ value $<0.05)$

*ICU: intensive care unit

*TBI: traumatic brain injury

Table (4): Receiver operating characteristic (ROC) curve analysis to predict ACS development during the first week of admission in ICU of patients with TBI

\begin{tabular}{|l|c|c|c|c|}
\hline \multicolumn{1}{|c|}{ Variable } & AUC & Cut off & Sensitivity & Specificity \\
\hline Age (years) & $\mathbf{0 . 8 5}$ & $>66$ years & 70.37 & 90.84 \\
\hline GCS & 0.68 & $=<6$ & 51.9 & 79.4 \\
\hline HR at admission & $\mathbf{0 . 8 2 8}$ & $>91$ & 96.3 & 74.6 \\
\hline $\begin{array}{l}\text { Mean arterial pressure at } \\
\text { admission }\end{array}$ & 0.766 & $>84$ & 100.0 & 42.9 \\
\hline RBCs at admission & 0.714 & $\leq 3.2 \times 10^{\wedge} 6$ & 62.96 & 73.02 \\
\hline HB at admission & $\mathbf{0 . 8 4 8}$ & $\leq 12$ & 66.67 & 93.65 \\
\hline Platelets at admission & 0.729 & $\leq 210$ & 55.56 & 98.41 \\
\hline Na at admission & 0.68 & $>147$ & 62.96 & 71.43 \\
\hline INR & $\mathbf{0 . 8 4 8}$ & $>1.21$ & 92.59 & 76.19 \\
\hline PTT & 0.622 & $>26$ & 40.74 & 85.71 \\
\hline
\end{tabular}

AUC: area under the ROC curve. "Accuracy is measured by AUC ${ }^{*} 90-1=$ excellent, * $.80-.90=$ good, ${ }^{*} .70-.80=$ fair, ${ }^{*} .60-.70=$ poor, ${ }^{*} .50-.60=$ fail.

*ICU: intensive care unit. *ACS: acute coronary syndrome *TBI: traumatic brain injury 
Table (5): Receiver operating characteristic (ROC) curve analysis for prediction of mortality during the first week of admission in ICU of patients developed ACS after TBI

\begin{tabular}{|l|c|c|c|c|}
\hline \multicolumn{1}{|c|}{ Variable } & AUC & Cut off & Sensitivity & Specificity \\
\hline Age (years) & $\mathbf{0 . 8 6 8}$ & $>67$ & 80.00 & 86.25 \\
\hline GCS & 0.712 & $\leq 6$ & 60.00 & 73.75 \\
\hline HR at admission & $\mathbf{0 . 8 9 2}$ & $>97$ & 100.00 & 71.25 \\
\hline $\begin{array}{l}\text { Mean arterial pressure } \\
\text { at admission }\end{array}$ & 0.688 & $>87$ & 90.00 & 48.75 \\
\hline RBCs at admission & 0.677 & $\leq 3.3 \times 10^{\wedge} 6$ & 70.00 & 60.0 \\
\hline HB at admission & 0.741 & $\leq 12$ & 70.00 & 81.25 \\
\hline Platelets at admission & $\mathbf{0 . 8 9 2}$ & $\leq 150 \times 10^{\wedge} 3$ & 90.00 & 96.25 \\
\hline Na at admission & 0.758 & $>149$ & 70.00 & 88.75 \\
\hline INR & $\mathbf{0 . 9 0 1}$ & $>1.28$ & 70.00 & 97.50 \\
\hline PTT & 0.719 & $>27$ & 70.00 & 97.50 \\
\hline
\end{tabular}

AUC: area under the ROC curve. "Accuracy is measured by AUC * $90-1=$ excellent, ${ }^{*}$ $.80-.90=$ good, ${ }^{*} .70-.80=$ fair, ${ }^{*} .60-.70=$ poor, ${ }^{*} .50-.60=$ fail.

*ICU: intensive care unit. *ACS: acute coronary syndrome *TBI: traumatic brain injury

Table (6): Regression analysis for associated risk factors for (ACS) in patients with (TBI).

\begin{tabular}{|l|c|c|}
\hline \multicolumn{1}{|c|}{ Independent variables } & Coefficient & P-value $^{*}$ \\
\hline Age (years) & $\mathbf{0 . 0 1 3 7 6}$ & $\mathbf{0 . 0 3 3 6}^{*}$ \\
\hline Echo_12hours & 0.1390 & 0.3889 \\
\hline GCS & $\mathbf{0 . 1 1 2 2}$ & $\mathbf{0 . 0 0 0 9}^{*}$ \\
\hline HB at admission & $\mathbf{0 . 5 1 2 0}$ & $\mathbf{0 . 0 0 0 1}^{*}$ \\
\hline Heart rate at admission & 0.003443 & 0.5081 \\
\hline Mean arterial pressure at admission & $\mathbf{0 . 0 2 5 1 3}$ & $\mathbf{0 . 0 0 0 8}^{*}$ \\
\hline INR at admission & $\mathbf{2 . 8 6 8 7}$ & $\mathbf{0 . 0 2 5 4}^{*}$ \\
\hline History of chronic disease & 0.03218 & 0.6979 \\
\hline Na at admission & $\mathbf{0 . 0 2 0 6 9}$ & $\mathbf{0 . 0 2 2 2}^{*}$ \\
\hline Platelets at admission & 0.002419 & 0.1367 \\
\hline PTT at admission & $\mathbf{0 . 0 7 3 8 8}$ & $\mathbf{0 . 0 0 1 9}$ \\
\hline RBCs at admission & 0.1066 & 0.5699 \\
\hline
\end{tabular}

* significant difference $(\mathrm{P}$ value $<0.05)$

*ACS: acute coronary syndrome *TBI: traumatic brain injury

\section{DISCUSSION}

In the present work, the acute coronary syndrome was reported in 27 patients $(30.0 \%)$ as evidenced by significantly elevated Troponin I, abnormal ECG and echocardiographic examination. Krishnamoorthy et al., (2014) reported that, ACS developed in $13.6 \%$. This percentage is lower than those of the present work. This could be explained by the severe TBI patients included in the present work as indicated by low GCS (6.4 \pm 1.2$)$ (Prathep et al., 2014).

In addition, Gregory and Smith (2012) reported that, ECG abnormalities were reported after TBI in $49-100 \%$, which is so higher than the present work. On the other side, Cuisinier et al., (2016) denied any major myocardial dysfunction at the early phase of TBI. However, after speckle tracking echocardiography, they reported minor changes in cardiac muscle. 
In the present study, ECG changes in ACS group were in the form of ST elevation in $(33.3 \%)$, ST depression in $(55.6 \%)$ and hyperacute $\mathrm{T}$ wave in $(11.1 \%)$. Gregory and Smith, (2012) demonstrated that ECG abnormalities after TBI such as ST segment depression and abnormal $\mathrm{T}$ waves can be associated with the development of a delayed ischemic neurological deficit, poor outcome, and death.

Abnormal echocardiographic findings were significantly increased in ACS when compared to negative group $(33.3 \%$ vs $6.3 \%$ respectively). Hasanin et al., (2016) reported abnormal echocardiographic examination in $(28 \%)$ of patients developed cardiac injury after TBI. In addition, Prathep and colleagues (2014) documented abnormal echocardiographic examination in $(22.3 \%)$ of TBI patients.

In the present study, cardiac troponin I(cTnI) was elevated in $43.3 \%$ at the first 24 hours and in $46.7 \%$ in the third day. These results are higher than that reported by Cai et al., (2016) who reported that, among 580 patients with TBI, $31 \%$ had detectable cTnI values at the time of admission. In addition, Salim et al., (2008) reported that, elevated cTnI were reported in $29.8 \%$. The possible explanation for increased cardiac troponin in the present work could be attributed to increased rate of chronic diseases and increased severity of TBI. The degree of cTnI increase among patients with TBI is associated with an increased risk of death and poor functional outcome in survivors (Tung et al., 2004).

TBI was predominant in males and this result is comparable to previous work by Cai et al., (2016) reported that, eligible patients were largely males $(70.8 \%)$. The reason might be that males are more vulnerable to road injuries and disputes (Munivenkatappa et al., 2016).

This study revealed that patients who developed ACS were significantly older in age when compared to negative group (68.7 \pm 6.4 vs $61.3 \pm 4.4$ years respectively). Advanced age is among the best independent predictors of worse outcome after TBI (Cai et al., 2016).

In this work, there was hemodynamic instability among studied patients. However, ACS group had significantly faster heart rate and higher mean arterial pressure at admission, but at the seventh day both groups were comparable. These changes are explained by dysfunction of autonomic nervous system (ANS) due to TBI. ANS activity, has been shown to correlate with an increased risk of cardiac complications, including an increased risk of arterial hypertension. (Kenney and Ganta, 2014).

Heart rate variability seems to play an important role in the development of ACS and this can explain the significant increase of heart rate in ACS group when compared to negative group. Orso et al., (2009) reported that, the pathophysiologic mechanism underlying the development of ACS is unique consisting in the instabilization of coronary atherosclerotic plaque and the final disruption of the fibrous cap. This harmful action leads to the activation of the coagulation cascade with an intravessel red thrombus formation with the consequence of a total or partial occlusion of the coronary vessel.

Lim and Smith, (2007); Krishnamoorthy (2017) demonstrated that the sympathetic hyperactivity associated with severe TBI causes direct injury to the myocardium. Catecholamine- 
induced vasoconstriction is intense, leading to hypertension and tachycardia and a secondary increase in myocardial oxygen demand without simultaneous increase in myocardial oxygen delivery, resulting in impairment of ventricular function even in absence of atherosclerosis.

CBC findings of the present study revealed that, there was anemia and thrombocytopenia among studied populations. Kramer et al., (2012) reported that, in ICU patients with TBI, the prevalence of anemia is about 22 to $69 \%$, depending if extracranial hemorrhage is present and the time of measurements. In addition, results of the present study agree with previous works (Kunadian et al., 2014; Uscinska et al., 2015).

Both INR and PTT were increased above normal values and platelet count was lower than normal values in the studied patients with significant increase in ACS reflected that, there is a stage of coagulopathy associated with traumatic brain injury. Different mechanisms were reported to explain such state of coagulopathy Laroche et al., (2012) reported that, platelet disorders (number and function), changes in anticoagulant factors, cell hypoperfusion and inflammation; all could contribute to the development of coagulopathy associated with TBI. Another mechanism is due direct brain tissue insults, which lead to the release of Tissue Factor (TF), which is a known activator of the extrinsic coagulation pathway. TF is liberated with acute structural brain lesions. Ischemia, secondary to hypercoagulation and microthrombi may also be a contributing factor (Abdelmalik et al., 2016).
Serum sodium was significantly increased in ACS group at admission, but not at $7^{\text {th }}$ day. This result is consistent with Maggiore et al., (2009), this hypernatremia could be attributed to the use of continuous-infusion hypertonic saline. Kolmodin et al., (2013) reported that hypernatremia is common following traumatic brain injury (TBI) and occurs from a variety of mechanisms, including hyperosmotic fluids, limitation of free water, or diabetes insipidus.

Our results also indicated that, it may be possible for clinicians to predict ACS in patient with TBI based on select clinical characteristics namely, age > 66 years, INR $>1.21$, HR at admission $>91$ and HB at admission $\leq 12$. These findings consistent with previous results (Gaddam et al., 2015).

As regard mortality, it was reported in 10 cases during the first week $(11.1 \%)$, 8 in ACS and 2 in negative group which is comparable to Krishnamoorthy et al., (2015) who reported that, in-hospital mortality occurred $10.2 \%$ of their studied subjects. In addition, Urdaneta et al., (2017) reported that, $16(11.5 \%)$ patients died during the hospitalization.

However, Jochems et al., (2018) reported a mortality rate of $33.0 \%$ during hospitalization. In addition, Cai et al. (2016) reported a mortality rate of $49.5 \%$. This higher rate of mortality could be attributed to different sample size, the type of trauma or the pre-existing cardiac disease. The autonomic dysfunction has also been shown to correlate with increased morbidity and mortality in moderate and severe TBI (Hendén et al., 2014).

Current study also documented a significant increased incidence of in- 
hospital mortality in ACS patients when compared to negative group $(29.6 \%$ vs $3.2 \%$ respectively). Our findings are consistent with Prathep et al., (2014); Hasanin et al., (2016), who concluded that cardiac injury was a mortality risk factor in patients with TBI.

The results of this study identified the increased age of patients, markers of coagulopathy, (prolonged INR \& thrombocytopenia) and increased HR at admission, as significant predictor factors for mortality in patients developed ACS after (TBI) and admitted to the ICU. These findings are in line with results of previous study (Lim and Smith 2007; Lin et al., 2015).

Our findings have several potential clinical implications in both intensive care and anesthetic practice in cases of severe TBI. The possible occurrence of ACS in the setting of TBI and its impact on patient outcome suggest that the clinicians need to keep in mind the probability of cardiovascular changes in patients with TBI. Echocardiography and search for ACS must be a routine in ICU after TBI. Otherwise, clinicians could be blamed for medical malpractice or negligence. Identification of high-risk patients after TBI is important to be able to arrange appropriate cardiac monitoring, an effective management of associated cardiac dysfunction and also to prevent cardiac morbidity and mortality, thus serving like a "shield" to medical-legal claims in addition to suits.

\section{CONCLUSIONS}

Results of the present work documented the development of acute coronary syndrome after traumatic brain injury. The development of the disease was associated with older age, increased chronic disease, severity of trauma, hemodynamic instability, anemia, coagulopathy and associated with increased ICU mortality. suggesting the influence of those factors on the development of ACS in patients with TBI. Watching those factors might amend the development of ACS in patients with TBI in clinical treatment and may prove useful in checking ACS after brain injuries.

\section{RECOMMENDATIONS}

- Further research is necessary to assess cardiac dysfunction broadly in traumatic head injuries, to recognize the impact of cardiac problems on patient outcomes, and to develop medical strategies that may either intercept or minimize the development of ACS and thus serving like a "shield" to medicallegal claims and suits.

- Enhancements in completeness and high quality of epidemiological data are needed for the detection of |associated high-risk populations and recognition of key targets regarding improved prevention and management of ACS due to TBI.

- Legal issues regarding traumatic brain injuries and the diagnosis and management of them should be recognized and appreciated by medical providers and used to balance the applicable medical and legal risks associated with their practices.

- Clinicians must know the efficient ways to translate the development in basic and scientific research into clinical practice and public.

- An adequate funding is required in the long-term TBI research to recognize 
best practices in addition to get the best outcomes.

- Implementation of prevention strategies and provision of optimum |medical care for TBI patients in ICU should become a priority for physicians

\section{REFERENCES}

Abdelmalik, P.; Boorman D.; Tracy, J., Jallo, J. and Rincon, F. (2016): Acute TraumaticCoagulopathy Accompanying Isolated Traumatic Brain Injury is Associated with Worse Long-Term Functional and Cognitive Outcomes. Neurocrit Care, 24:361370

Amsterdam, E.A.; Wenger, N.K.; Brindis, R.G.; Casey, D.E.; Ganiats, T.G. et al. (2014): AHA/ACC Guideline for the Management of Patients with Non-ST-Elevation Acute Coronary Syndromes: A Report of the American College of Cardiology/American Heart Association Task Force on Practice Guidelines. Circulation, 25:130 - 40.

Cai, S.; Bonds, B.; Hu, P. and Stein, D. (2016): The role of cardiac troponin I in prognostication of patients with isolated severe traumatic brain injury. J Trauma Acute Care Surg, 80:477483.

Cuisinier, A.; Maufrais, C.; Payen, J.; Payen, J.; Nottin, S. et al. (2016): Myocardial function at the early phase of traumatic brain injury: a prospective controlled study. Scand J Trauma Resusc Emerg Med, 24:129.

Esterov, D. and Greenwald, B. (2017): Autonomic Dysfunction after Mild Traumatic Brain Injury Brain Sci,7(8). pii: E100. doi:10.3390/brainsci7080100.
Gaddam, S.; Buell, T. and Robertson, C. (2015): Systemic manifestations of traumatic brain injury. Handb Clin Neurol,127:205-18. doi: 10.1016/B978-0-444-52892-6.000143.

Gregory, T. and Smith, M. (2012): Cardiovascular complications of brain injury. Continuing Education in Anesthesia. Critical Care \& Pain, 12 (2): 67-69.

Hasanin, A.; Kamal, A.; Amin, S.; Zakaria, D.; El Sayed, R.; Mahmoud, K. and Mukhtar, A. (2016): Incidence and outcome of cardiac injury in patients with severe head trauma. Scand J Trauma Resusc Emerg Med, 24:58. doi:10.1186/ s13049-016-0246-z.

Hendén, P.; Söndergaard, S.; Rydenhag, B..; Reinsfelt, B..; Ricksten, S. and Åneman, A. (2014): Can Baroreflex Sensitivity and Heart Rate Variability Predict Late Neurological Outcome in Patients with Traumatic Brain Injury? J. Neurosurg. Anesthesiol, 26:50-59. doi:

10.1097/ANA.0b013e3182a47b62.

[PubMed] [CrossRef] [Google Scholar]

Jochems, D.; van Wessem, K. and Houwert, R. (2018): Outcome in Patients with Isolated Traumatic Brain Injury. Hindawi Critical Care Research and Practice Volume 2018, Article ID 3769418, 7 pages

Kenney, M.J. and Ganta, C.K. (2014): Autonomic nervous system and immune system interactions. Compr. Physiol, 4:1177-1200.

Kolmodin, L.; Sekhon, M.; Henderson, W.; Turgeon, A. and Griesdale, D. 
(2013): Hypernatremia in patients with severe traumatic brain injury: a systematic review. Ann Intensive Care, 3(1):35. doi: 10.1186/21105820-3-35.

Kramer, A. and Roux, P. (2012): Red blood cell transfusion and transfusion alternatives in traumatic brain injury. Curr Treat Options Neurol,14(2):150163.

Krishnamoorthy, V.; Prathep, S. and Sharma, D. (2014): Association between electro-cardiographic findings and cardiac dysfunction in adult isolated traumatic brain injury. Indian J Crit Care Med, 18(9):570-4.

Krishnamoorthy, V.; Rowhani-Rahbar, A.; Chaikittisilpa, N.; Gibbons, E.; Rivara, F. et al. (2017): Association of early hemodynamic profile and the development of systolic dysfunction following traumatic brain injury. Neurocrit Care, 26:379-387.

Krishnamoorthy, V.; Vavilala, M.; Mills, B. and owhani-Rahbar, A. (2015): Demographic and clinical risk factors associated with hospital mortality after isolated severe traumatic brain injury: a cohort study. Journal of Intensive Care, 3:46.

Kunadian, V.; Mehran, R.; Lincoff, A.; Feit, F.; Manoukian, S. et al. (2014): Effect of anemia on frequency of short- and long-term clinical events in acute coronary syndromes (from the acute catheterization and urgent intervention triage strategy trial). Am J Cardiol, 114:1823-9.

Leitman, I.M. (2012): Understanding the brain-heart axis in neurological trauma. J Surg Res, 173: e33-e35.

Lim, H. and Smith, M. (2007): Systemic complications after head injury: a clinical review. Anaesthesia, 62, pages 474-482. doi:10.1111/j.13652044.2007. 04998.x

Lin, C.; Chang, C.; Sun, C.; Li, T.; Chen, L.; Chang, S. and Wu, Y. (2015): Platelet count and early outcome in patients with spontaneous cerebellar hemorrhage: a retrospective study. PLoS One.17;10(3): e0119109. doi: $\quad 10.1371 /$ journal.pone.0119109. eCollection 2015.

Linden, A. (2006): Measuring diagnostic and predictive accuracy in disease management: an introduction to receiver operating characteristic (ROC) analysis. J Eval Clin Pract. 12:132-9. doi: 10.1111/j.13652753.2005.00598.x

Maggiore, U.; Picetti, E.; Antonucci, E.; Parenti, E.; Regolisti, G.; Mergoni, M. et al. (2009): The relation between the incidence of hypernatremia and mortality in patients with severe traumatic brain injury. Crit Care,13(4): R110. doi: 10.1186/cc7953. Epub 2009 Jul 7.

Munivenkatappa, A.; Agrawal, A.; Shukla, D.; Kumaraswamy, D. and Devi, B. (2016): Traumatic brain injury: Does gender influence outcomes? Int J Crit Illn Inj Sci, 6(2):70-3 doi: 10.4103/22295151.183024PMID: 27308254.

Orso, F.; Baldasseroni, S. and Maggioni, A. (2009): Heart Rate in Coronary Syndromes and Heart Failure. Progress in CardiovascularDiseases,52:38-45.

Prathep, S.;Sharma, D.; Hallman, M.; Joffe, A.; Krishnamoorthy, V.; Mackensen,G.et al.(2014): Preliminary report on cardiac dysfunction after isolated traumatic 
brain

Jan;42(1):1427.doi:10.1097/CCM.0b0 $13 \mathrm{e} 318298 \mathrm{a} 890$

Salim, A.; Hadjizacharia, P.; Brown, C.; Inaba, K.; Teixeira, P. et al. (2008). Significance of troponin elevation after severe traumatic brain injury. J Trauma, 64:46-52.

Stocchetti, N.; Carbonara, M.; Citerio, G.; Ercole, A.; Skrifvars, M. et al. (2017): Severe traumatic brain injury: targeted management in the intensive care unit. Lancet Neurol, 16: 452-64.

Thygesen, K.; Alpert, J.; Jaffe, A.; Simoons, M.; Chaitman, B. et al. (2012): Third universal definition of myocardial infarction. J Am Coll Cardiol, 60:1581-98.

Tung, P.; Kopelnik, A.; Banki, N. et al. (2004): neurocardiogenic injury after subarachnoid hemorrhage. Stroke, 35: $548-51$

Urdaneta, A.; Fink, K.; RowhaniRahbar, A.; Rowhani-Rahbar, A3.; Vavilala, M. et al. (2017): Radiographic and Clinical Predictors of Cardiac Dysfunction Following Isolated Traumatic Brain Injury. Journal of Intensive Care Medicine,32(2):151-157.

Uscinska, E.; Sobkowicz, B.; Sawicki, R.; Kiluk, I.; Baranicz, M. et al. (2015): Parameters influencing inhospital mortality in patients hospitalized in intensive cardiac care unit: is there an influence of anemia and iron deficiency? Intern Emerg Med, 10:337-44. 


\section{مدى حدوث الإصابة بمتلازمة الثريان التاجي الحادة بعد إصابة الاماغ في وحدة العناية المركزة (العوامل

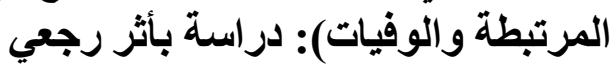 \\ عادل الهادي دياب1 ـ محمود حلمي حسين2 ــ أمل عبد المجيد أحمد 3

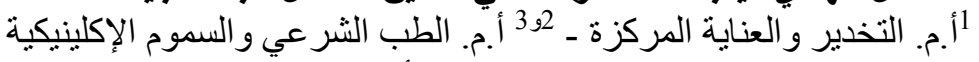

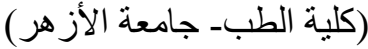 \\ الملخص العربيى}

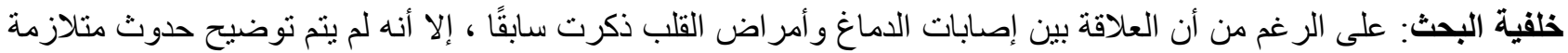

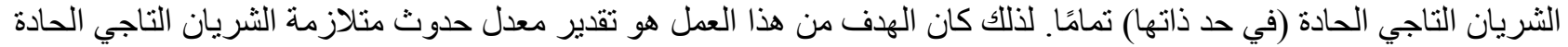

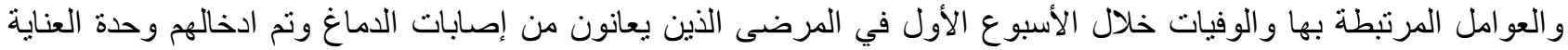
المركزة.

منهجية البحث: أجريت هذه الدراسة بأثر رجعي وشملت جميع المرضى البالغين الذين يعانون من إصابات في الدماغ في وحدة

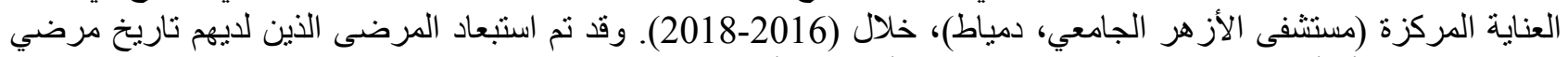

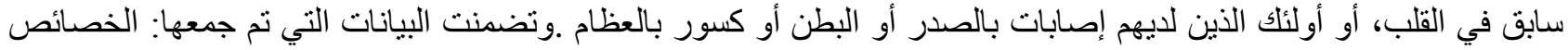

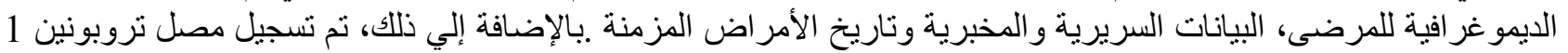

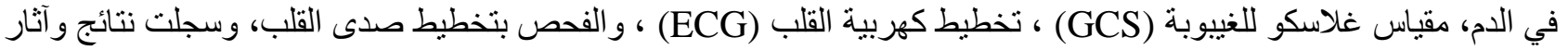
ذللك علي المرضى. وقد تم تقسيم المرضى إلى مجمو عتين وفقا لظهور متلازمة الثريان التاجي الحادة من عدمه.

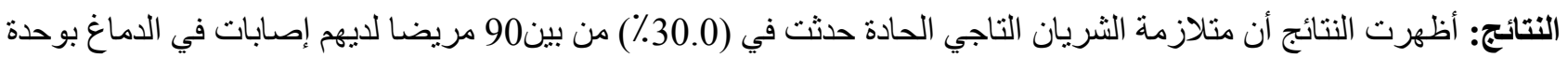

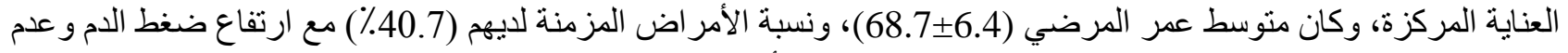

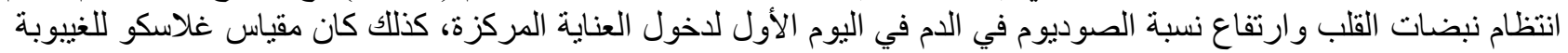
(GCS)

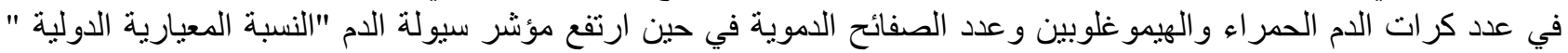

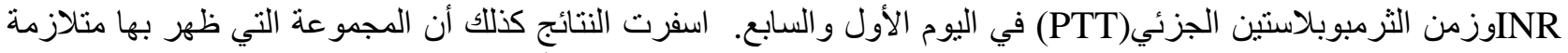

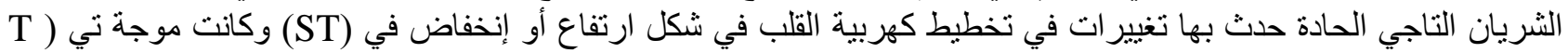

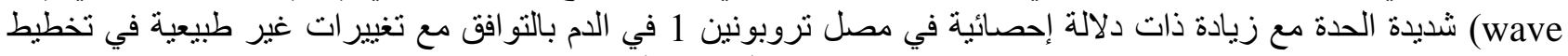

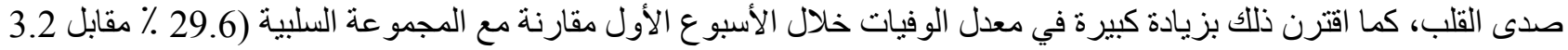
\%

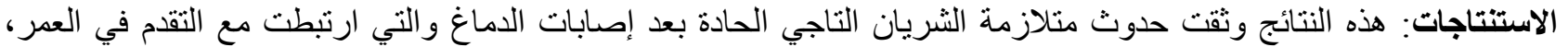

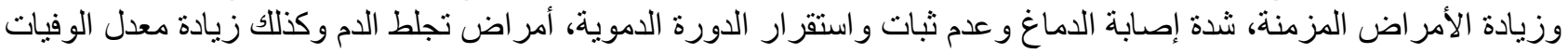

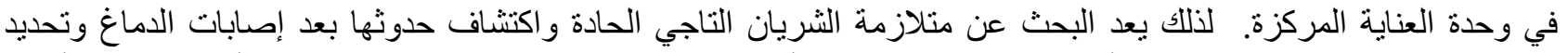

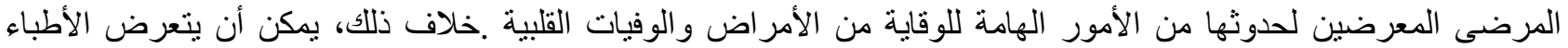
للمساءلة القانونية بسبب الإهمال الطبي. الكلمات المفتاحية: إصابات الدماغ، تغييرات تخطيط القلب، متلازمة الثريان التاجي الحادة ، تروبونين القلب 1 ، تخطيط صدى القلب. 